\title{
nature
}

\section{Think of a number and double it}

Even with the US federal budget in surplus, the scientific community needs to present a more sophisticated argument than merely demanding an across-the-board doubling of research funding for government agencies.

S cientific societies in the United States are working to muster support in the Senate for a bill — the National Research Investment Act, or S1305 - that would double civilian research and development spending, from $\$ 34$ billion to $\$ 68$ billion a year, over the next ten years. The societies view the bill not merely as a desirable goal, but as a way of drawing together science's fragmented base of political support. But the measure is unlikely to pass into law, having attracted only 15 supporters since it was put forward last October by two Republican and two Democrat senators (see page 4).

One of S1305's greatest strengths is its simplicity. By increasing the level of support at all science agencies at once, it avoids painful and unseemly arguments about which deserve most support. This has enabled more than a hundred groups representing the scientific and engineering communities to unite behind the measure to an unprecedented degree, and to deliver to the senators a straightforward message in the name of some three million scientists and engineers.

But this lack of sophistication may also be the measure's undoing. The arguments for doubling resources for each of the US federal government's research and development activities are, to put it politely, underdeveloped. Indeed there are some areas of government research activity that would not deserve more money even if the citizenry was queueing up at the laboratory gates to deposit more tax dollars directly.

Furthermore, if the National Research Investment Act were to gather sufficient support to reach the Senate floor, the sheer amount of money involved - $\$ 170$ billion in extra spending over ten years would, as Senator Jay Rockefeller (Democrat, West Virginia) has observed, smoke out enemies that science never even knew it had.

At heart, therefore, S1305 may be well-intentioned, but it is also flawed. It attempts to deny a rational science policy by implying that both the research enterprise and society stand to benefit from a large and indiscriminate increase in current civilian research spending. But it ill becomes the community to argue against an intelligent and highly selective science policy. As often stated during the recent years of budgetary restraint, US science needs more honest and more vigorous identification of priorities. It would be the height of folly for the community to turn its back on this requirement the moment a balanced federal budget is in sight.

The message of $\mathrm{S} 1305$ is simple and easy to explain: "spend". This is already a distressingly familiar refrain in Washington, where major special interest groups, notably the military and the roads lobby, are preparing for a full-frontal assault on the spending limits agreed in last year's balanced budget between President Bill Clinton and the Congress. These interest groups carry heavier artillery than the science community can ever hope to muster.

Some argue that authorization bills — which set theoretical limits on future government spending — such as $\mathrm{S} 1305$ are unimportant, as real spending decisions are taken by appropriations committees on an annual basis. But if the Senate and the House of Representatives were to confront some jurisdictional issues and actually pass authorization bills for science agencies, these would indeed carry influence, as they already do in other parts of the government. It is therefore to be hoped that senators such as Bill Frist (Republican, Tennessee), who have expressed reservations about S1305, will work with its sponsors to develop a more realistic alternative, and then work with colleagues in the House of Representatives to pass it.

The community's top priority this year is to extend the aura that surrounds the National Institutes of Health. Considerable progress has already been made in educating Congress about the importance of the National Science Foundation in supporting health and other government missions. Other such connections, including the role of Department of Energy facilities in supporting the life sciences, remain to be better understood and articulated (see page 3 ). Science will ultimately be sold to the Congress only on the intelligent explanation of each part of the research enterprise.

\section{Challenges ahead}

\section{The success of Britain's Technology Foresight exercise is no grounds for complacency about its successor.}

$\square$ oes good science inexorably lead to new products and economic growth (the 'science push' model)? Or conversely, does a dynamic industrial base act as the spur for novel scientific ideas ('technology pull')? For the past five years, Britain's Technology Foresight exercise has attempted to finesse this conundrum by suggesting a third approach, namely that innovation and growth emerge from a complex interaction between science and the market place, involving close communication and substantial feedback between actors in the two separate fields.

Certainly the apparent success of the exercise, indicated by the British government's recent announcement that it is launching a second programme, called merely Foresight (see page 8 ), has confounded sceptics who initially complained that it would inevitably place a strait-jacket on British science, and degenerate into a doomed attempt to pick technology 'winners'. Success is based on the way Technology Foresight has become a device for injecting a user dimension into debates on scientific priorities that has proved acceptable to political parties of both left and right. At its best, Technology Foresight can represent the 'bottom-up' approach to setting research priorities that fits well with the flexible, competitive economies of the late 1990s. It is perhaps not surprising that similar techniques are now being explored in countries as diverse as India and Germany (see page 7).

But Britain must not rest on its laurels. There are still plenty of problems with the implementation of both Technology Foresight and its successor, such as a failure to penetrate sufficiently the small and medium-sized businesses that represent the most innovative sector of the economy. The effectiveness of targeting Foresight activities around broad social goals, as proposed for the second exercise, has yet to be proved. Finally, careful prioritization is no alternative to the adequate funding of the science base. The cultural change in British science over the past five years means that additional funding is now more important than ever - not that it is no longer required. 